\title{
TGF- $\beta$ signaling is required for the function of insulin-reactive T regulatory cells
}

\author{
Wei Du, ${ }^{1}$ F. Susan Wong, ${ }^{2}$ Ming O. Li, ${ }^{3}$ Jian Peng, ${ }^{1}$ Hao Qi, ${ }^{1}$ \\ Richard A. Flavell, ${ }^{3}$ Robert Sherwin, ${ }^{1}$ and Li Wen'1
}

\begin{abstract}
1Section of Endocrinology, Yale University School of Medicine, New Haven, Connecticut, USA. ${ }^{2}$ Department of Cellular and Molecular Medicine, School of Medical Sciences, University of Bristol, Bristol, United Kingdom. ${ }^{3}$ Section of Immunobiology and Howard Hughes Medical Institute, Yale University School of Medicine, New Haven, Connecticut, USA.
\end{abstract}

\begin{abstract}
We have previously isolated insulin-reactive Tregs from diabetic NOD mice designated 2H6, from which TCR transgenic mice were generated. The $\mathrm{T}$ cells from these $2 \mathrm{H} 6$ transgenic mice recognize insulin but have suppressive properties in vitro. They protect NOD mice in vivo from spontaneous development of diabetes and adoptive transfer of disease caused by polyclonal diabetogenic spleen cells as well as the highly diabetogenic monoclonal BDC2.5 TCR transgenic $T$ cells that recognize an islet granule antigen. Using cells from both NOD and BDC2.5 mice that express a dominant-negative TGF- $\beta$ receptor type II (TGF- $\beta$ DNRII), we show that $2 \mathrm{H} 6 \mathrm{~T}$ cells protected from disease by producing TGF- $\beta$ and that the ability of the target diabetogenic T cells to respond to TGF- $\beta$ was crucial. We further demonstrate that TGF- $\beta$ signaling in $2 \mathrm{H} 6$ cells was important for their protective properties, as $2 \mathrm{H} 6$ cells were unable to protect from adoptive transfer-induced diabetes if they were unable to respond to TGF- $\beta$. Thus, our data demonstrate that insulin-specific regulatory cells protect from diabetes by virtue of their production of TGF- $\beta 1$ that acts in an autocrine manner to maintain their regulatory function and acts in a paracrine manner on the target cells.
\end{abstract}

\section{Introduction}

Insulin is an important autoantigen in human type 1 diabetes mellitus (T1D). This is supported by the following findings: (a) a gene linked to T1D that controls expression of insulin in the thymus and the pancreas is located in the VNTR region of the insulin promoter (1); (b) the level of insulin expression in the thymus influences genetic susceptibility to T1D $(2,3)$, presumably by regulating the selection of insulin-specific T cells; (c) anti-insulin antibodies are frequently present in young prediabetic and diabetic patients (4); and (d) a subset analysis of the large Diabetes Prevention Trial-1 has indicated that oral insulin may protect high-risk subjects (5, $6)$. In the NOD mouse, many islet-reactive $\mathrm{T}$ cells invading the islet are insulin specific $(7,8)$, and, most importantly, insulin-reactive $\mathrm{T}$ cells are capable of adoptively transferring diabetes in NOD mice $(7,9)$. These cells appear to recognize insulin $B$ chain in the region of peptide 9-23 $(9,10)$. Interestingly, insulin B chain 9-23 peptide also stimulates peripheral blood $\mathrm{T}$ cell responses in newly diagnosed and high-risk patients (11). The importance of insulin as an autoantigen is further underscored by data demonstrating that insulin injections protect NOD mice from developing autoimmune diabetes $(12,13)$. Subsequent data demonstrating that oral insulin or metabolically inactive insulin B chain and insulin B chain peptide 9-23 injections exert similar effects provide strong evidence that insulin therapy in mice does not act metabolically on the $\beta$ cell but rather induces a regulatory immune response (14-16).

There are a number of different types of regulatory cells. Naturally arising $\mathrm{CD} 4^{+} \mathrm{CD} 25^{+} \mathrm{T}$ cells in the thymus are released to the periphery. These cells express the inhibitory molecule CTL-associated anti-

Nonstandard abbreviations used: CTLA-4, CTL-associated antigen 4; CY, cyclophosphamide; GAD, glutamic acid decarboxylase; PLN, pancreatic lymph node; T1D, type 1 diabetes mellitus; TGF- $\beta$ DNRII, dominant-negative TGF- $\beta$ receptor type II. Conflict of interest: The authors have declared that no conflict of interest exists. Citation for this article: J. Clin. Invest. 116:1360-1370 (2006). doi:10.1172/JCI27030. gen 4 (CTLA-4) and the forkhead transcription factor FoxP3, and they are responsible for controlling physiological and pathological immune responses (17). These suppressive $T$ cells function through a variety of mechanisms, which include direct contact as well as production of the inhibitory cytokines IL-10 and TGF- $\beta$. Separate subsets of Tregs can be induced by antigen stimulation in vivo. Th3 cells, which produce TGF- $\beta$, are stimulated by the oral administration of whole proteins (18). More recently, it was shown that the IL-10-secreting type 1 Treg $(\operatorname{Tr} 1)$ subset of cells can be induced by nasal administration of short peptides $(19,20)$. In addition, whether regulatory cells of known antigen specificity are able to inhibit cells with the same antigen specificity or whether bystander suppression can occur has varied with the system under study $(18,21,22)$.

There is substantial evidence for a regulatory component to the immune response in T1D. In NOD mice, progression to overt diabetes is gradual rather than acute. Similarly, in humans, overt diabetes may require years to become apparent after the appearance of islet cell antibodies, implying that the autoimmune response is downregulated. A number of studies suggest that insulin is capable of generating a diabetes-protective immune response. NOD mice, given oral insulin, generate Tregs (i.e., Th2 or Th3 cells) capable of producing IL-4 or TGF- $\beta(14,15,23)$. We have previously isolated, from pancreatic lymph node (PLN) cells of a diabetic NOD mouse, a cloned T cell line (24), designated $2 \mathrm{H} 6$, that recognizes insulin (specifically B chain peptide 12-25 or 9-23), secretes IFN- $\gamma$ and TGF- $\beta$, and has a striking ability to block both the adoptive transfer of diabetes in NOD.scid recipients and the spontaneous development of diabetes in NOD mice. The specificity of the regulatory clone for insulin provides it with a means of targeting the islet, thereby allowing it to direct its secretory product TGF- $\beta$, locally, at diabetogenic cells reaching the islet.

We have now generated 2H6 TCR transgenic NOD mouse lines. Here we report the generation and characterization of this TCR transgenic NOD mouse. Like the parental cells, transgenic 2H6 
A
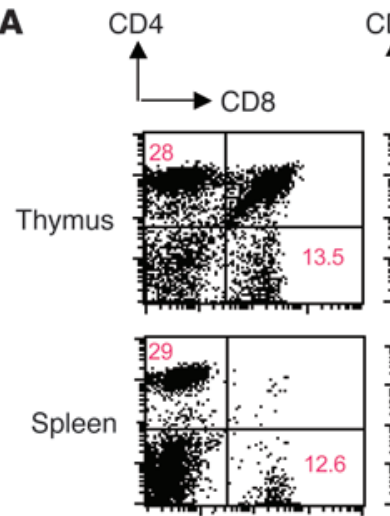

PLNs

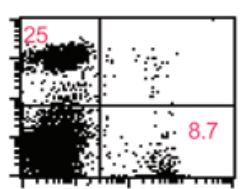

ALNs

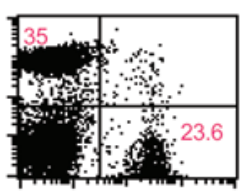

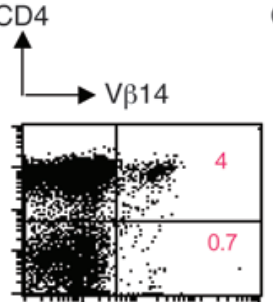
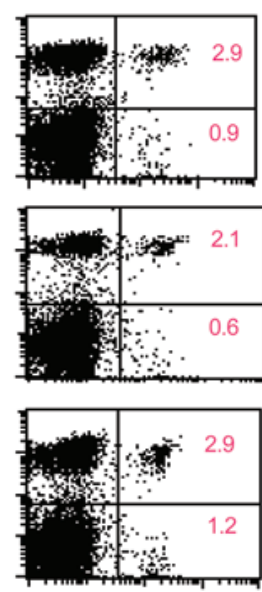

$2 \mathrm{H}_{6} \mathrm{Tg}^{-}$
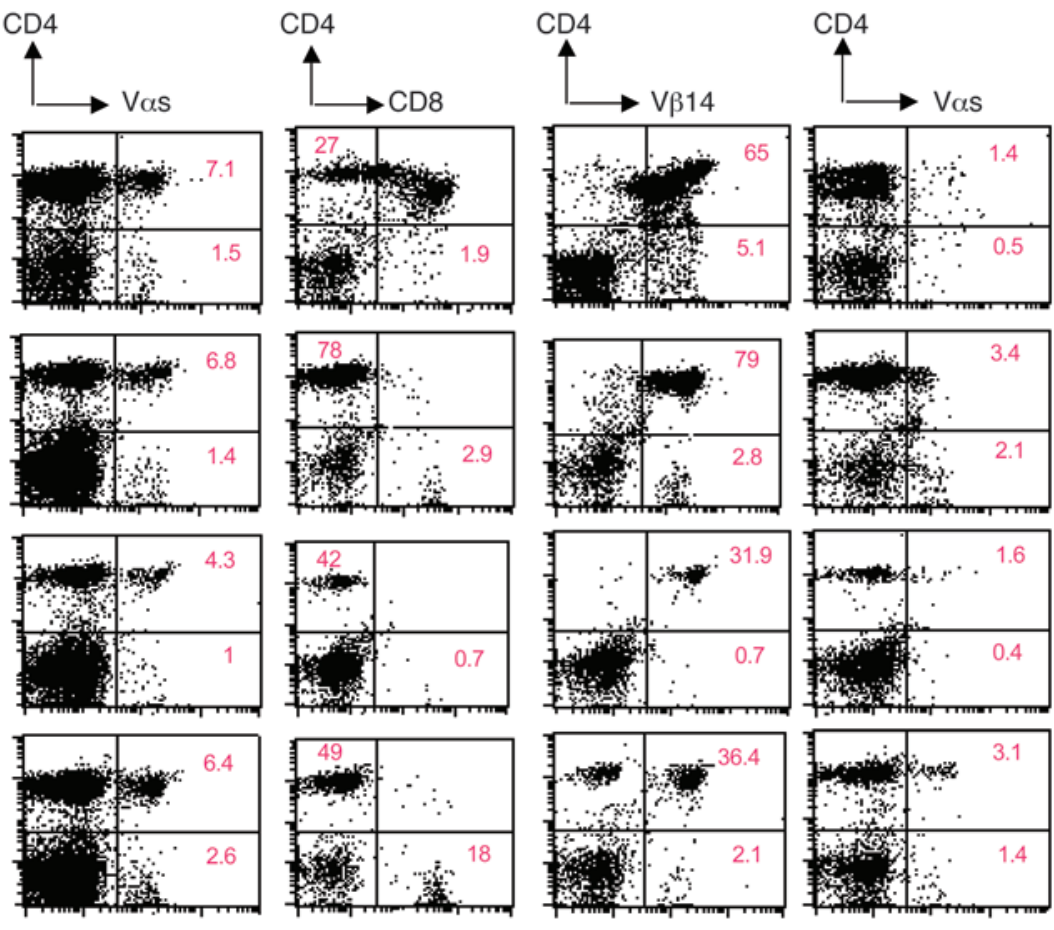

B
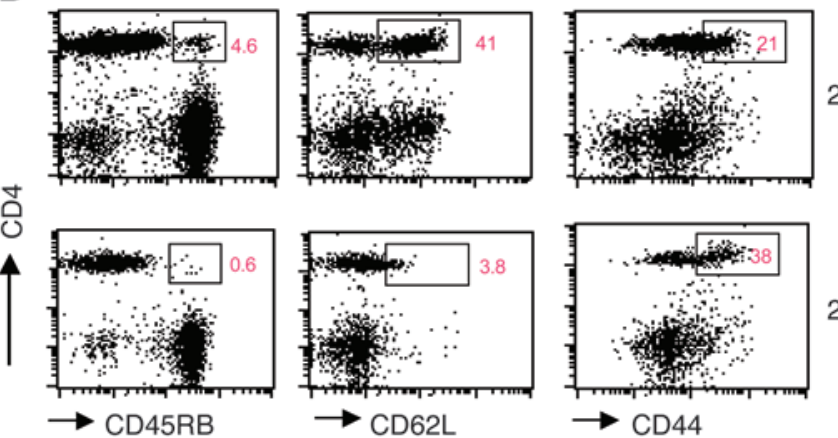

$2 \mathrm{H} 6 \mathrm{Tg}$
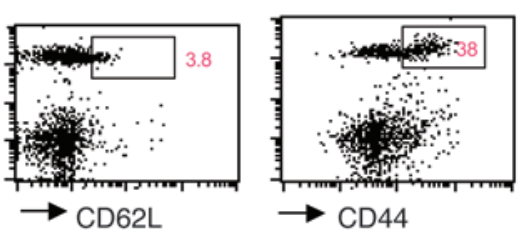

$2 \mathrm{H} 6 \mathrm{Tg}^{+}$

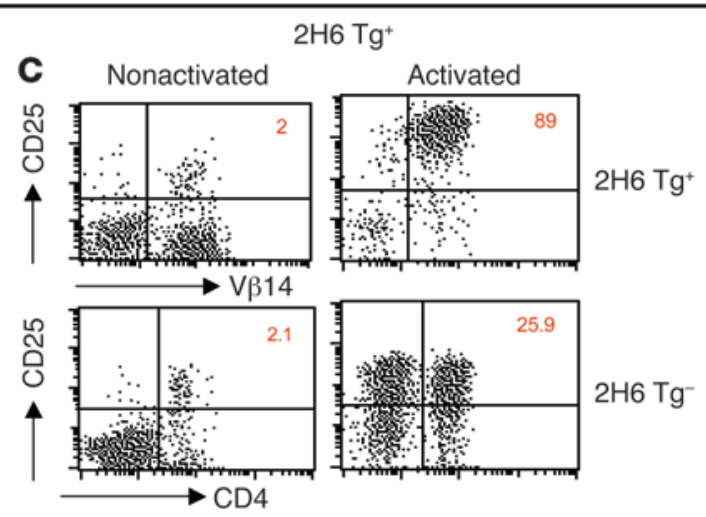

Figure 1

2H6 TCR transgene expression and phenotypic analysis of the transgenic mice. (A) Expression of $2 \mathrm{H} 6 \mathrm{TCR}$ transgene. Thymocytes, splenocytes, and lymphocytes isolated from pancreatic and axillary lymph nodes (PLNs and ALNs, respectively) of 2H6 TCR transgenic (line 50) and nontransgenic NOD mice were stained with anti-V $\beta 14$, anti-CD4, anti-CD8, and a cocktail of anti-V $\alpha$ mAbs and analyzed by flow cytometry. The numbers in quadrants represent the percentage of positive cells among the total cells analyzed. (B) $2 \mathrm{H} 6$ transgenic T cells express an effector/memory-like phenotype. Lymphocytes isolated from spleen of nontransgenic (top panel) and 2H6 TCR transgenic (bottom panel) NOD mice were stained with CD4, CD45RB, CD62L, and CD44. The cells were then analyzed by flow cytometry. (C) CD25 expression of splenic CD4+ $\mathrm{T}$ cells in $2 \mathrm{H} 6 \mathrm{TCR}$ transgene-positive and -negative NOD mice. Splenocytes were harvested from both types of mice and stained with CD4 and CD25 with and without anti-CD3 stimulation. The numbers in the top right quadrants represent the percentage of positive cells among the total cells analyzed.

cells also secrete a notable amount of IFN- $\gamma$ and TGF- $\beta$ upon TCR ligation. NOD mice expressing the 2H6 TCR transgene are completely protected from diabetes development. Furthermore, cells from the transgenic mouse can differentiate into potent regulatory cells that have the ability to protect NOD mice from attack by spleen cells from diabetic mice as well as the highly diabetogenic cells from the BDC2.5 transgenic mouse. This unique regulatory TCR transgenic model will not only facilitate our understanding of the mechanisms of how Tregs work but also facilitate the design of better therapeutic strategies to restrain autoimmunity effectively.

\section{Results}

$2 H 6$ TCR transgenic NOD mice express 2 H6 TCR. Three 2 H6 Treg TCR transgene-positive founders were generated, and all showed germline transmission of the transgene. The expression of the $2 \mathrm{H} 6 \mathrm{TCR}$ transgene was screened for by genomic PCR using 2H6-specific $\mathrm{V} \alpha / \mathrm{J} \alpha$ and $\mathrm{V} \beta / \mathrm{J} \beta$ primers and confirmed by flow cytometry using $\mathrm{mAb}$ against $\mathrm{V} \beta 14$. Over $97 \%$ of $\mathrm{CD}^{+} \mathrm{T}$ cells expressed $\mathrm{V} \beta 14$ in transgene-positive mice, whereas only $5-7 \%$ of $\mathrm{CD}^{+} \mathrm{T}$ cells stained positively for the endogenous V $\beta 14$ TCR in transgene-negative control mice (Figure 1A). There was no difference in the expression of transgenes in different lines detected by mAb against $\mathrm{V} \beta 14$ 
A
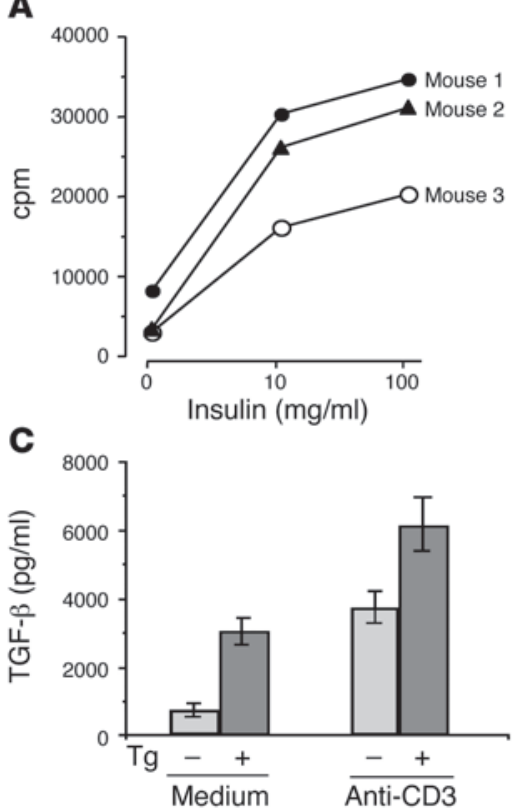

$\mathbf{E}$

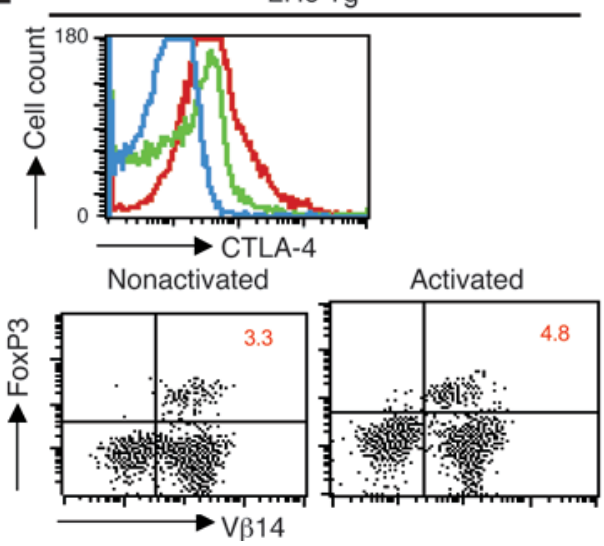

B

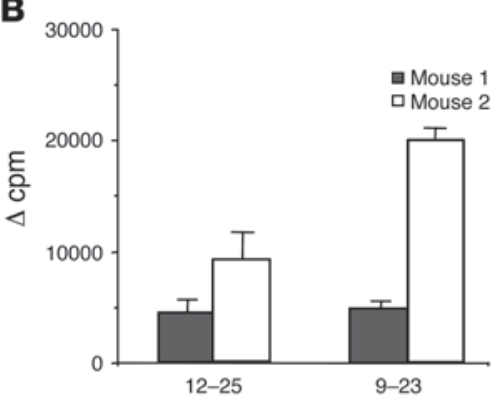

D
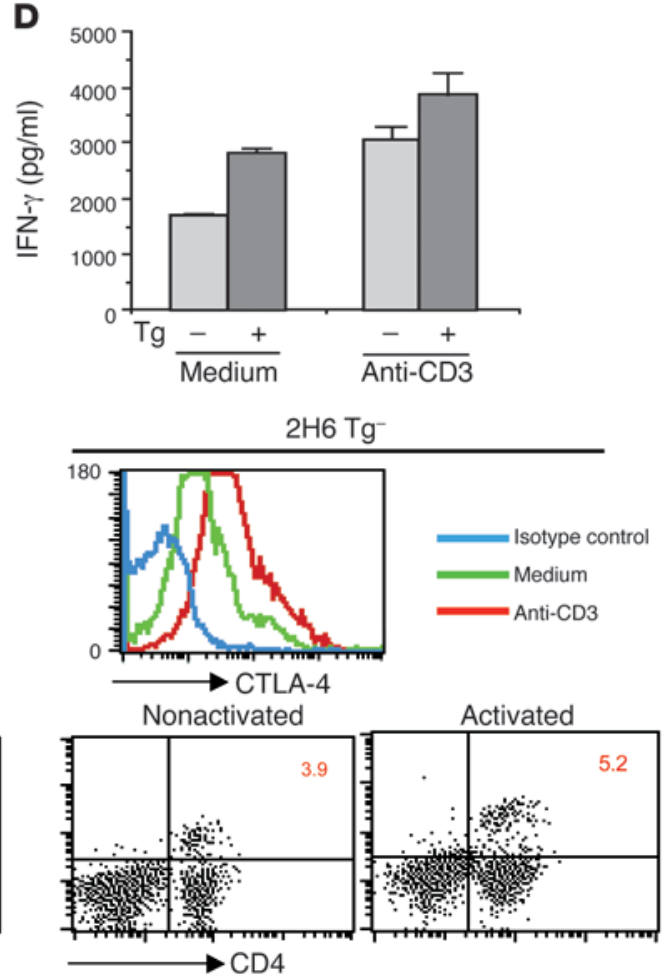

Figure 2

Insulin reactivity, cytokine profile, and CTLA-4 and FoxP3 expression of 2H6 TCR transgenic T cells. (A) Insulin reactivity of $2 \mathrm{H} 6$ TCR transgenic T cells. Splenocytes from 3 randomly selected $2 \mathrm{H} 6$ TCR transgenic mice (1 from line 22 and 2 from line 50 ) were used in the proliferation assay. Cells ( $10^{5}$ per well) were cultured in Click's medium for 72 hours (in triplicate). ${ }^{3} \mathrm{H}$-thymidine was added for the last $16-18$ hours. (B) The reactivity to insulin B chain peptide $12-25$ or 9-23 was also analyzed using the same protocol as in $\mathbf{A}$. Results are illustrated as $\Delta \mathrm{cpm}=$ proliferation with peptide - proliferation with medium. (C and D) TGF- $\beta$ (C) and IFN- $\gamma$ (D) production from cells of transgene-negative and -positive NOD mice. Splenocytes $\left(10^{5}\right.$ cells per well) from both types of mice were cultured in Click's medium in the presence or absence of anti-CD3 (1:100 dilution of 2C11 hybridoma supernatant) for 48 hours (in triplicate). The culture supernatants were collected. IFN- $\gamma$ and TGF- $\beta$ contents were measured with an IFN- $\gamma$ ELISA kit (BD Biosciences) and a TGF- $\beta$ ELISA kit (R\&D Systems). (E) Expression of CTLA-4 and FoxP3 in transgene-positive and -negative NOD mice. Splenocytes (106) from both types of mice were stained for intracellular CTLA-4 and FoxP3 expression with or without TCR stimulation (anti-CD3). Monoclonal antibodies against CTLA-4 and FoxP3 were purchased from BD Biosciences and eBioscience, respectively. The staining was carried out according to the manufacturers' protocols. The numbers in the top right quadrants represent the percentage of positive cells among the total cells analyzed.

(Supplemental Figure 1A; supplemental material available online with this article; doi:10.1172/JCI27030DS1). As expected, the expression of the $2 \mathrm{H} 6 \mathrm{TCR}$ transgene blocked $\mathrm{CD}^{+} \mathrm{T}$ cell development, and there was no difference in the inhibition of $\mathrm{CD}^{+} \mathrm{T}$ cell expression among the 3 transgenic lines (Supplemental Figure 1A). Similarly, there was, notably, no T cell deletion observed in any of the transgenic lines in the thymus and periphery in spite of the insulin specificity of the TCR. The total cell numbers in both thymus and spleen of the $2 \mathrm{H} 6$ transgenic mice were comparable to those of transgene-negative littermates (Supplemental Figure 1B). This suggests that there was no obvious deletion of selfantigen-reactive $2 \mathrm{H} 6 \mathrm{~T}$ cells in the central and peripheral lymphoid organs. The expression of nontransgenic $V \alpha$ genes was determined by staining with a cocktail of commercially available mAbs against $V \alpha 2, V \alpha 3.2$, Vo8.3, and Vo11 (Vo11.1 and 11.2). It appears that $2 \mathrm{H} 6$ transgene expression somewhat suppressed the endogenous $V \alpha$ gene expression, as many $2 \mathrm{H} 6$ mice had a reduced number of $V \alpha 2$, Va3.2, Va8.3, Va11.1, and Vo11.2 compared with the transgene-negative littermates (Figure 1A). It is interesting that the reduction of endogenous $\mathrm{V} \alpha$-expressing $\mathrm{T}$ cells was greater in thymus and PLNs of $2 \mathrm{H} 6$ mice (Figure 1A). There was no obvious endogenous $\mathrm{V} \beta$ gene usage when a cocktail of $\mathrm{mAbs}$ against $\mathrm{V} \beta 2, \mathrm{~V} \beta 3, \mathrm{~V} \beta 4$, $\mathrm{V} \beta 5$, V $\mathrm{V} \beta 6, \mathrm{~V} \beta 7, \mathrm{~V} \beta 8, \mathrm{~V} \beta 10, \mathrm{~V} \beta 11$, $\mathrm{V} \beta 12$, and $\mathrm{V} \beta 17$ was used (data not shown). Again, no difference was observed among the 3 lines in the expression of either endogenous $V \alpha$ or $V \beta$ genes (data not shown). Further characterization of the transgenic mice therefore focused on only 2 of the 3 founder lines (line 22 and line 50).

Phenotype, insulin specificity, and cytokine profile of 2 H6 TCR transgenic T cells. Phenotypic analysis of $2 \mathrm{H} 6$ transgenic and nontransgenic NOD mice revealed that most of the $2 \mathrm{H} 6 \mathrm{~T}$ cells did not express a genuinely naive phenotype (CD44low, CD45RB high, and $\left.\mathrm{CD} 62 \mathrm{~L}^{\text {high }}\right)$. Instead, $2 \mathrm{H} 6$ transgenic $\mathrm{T}$ cells, when compared with $\mathrm{T}$ cells from nontransgenic NOD mice (Figure 1B, top panel), showed $\mathrm{CD} 44^{\text {high/medium }}, \mathrm{CD} 45 \mathrm{RB}^{\text {medium/low }}$, and CD $62 \mathrm{~L}^{\text {low }}$, a phenotype that more resembles that of effector/memory cells (Figure 1B, bottom panel). It is interesting that transgenic $2 \mathrm{H} 6 \mathrm{~T}$ cells expressed little CD25 (Figure 1C), a marker for a subset of Tregs, 
A

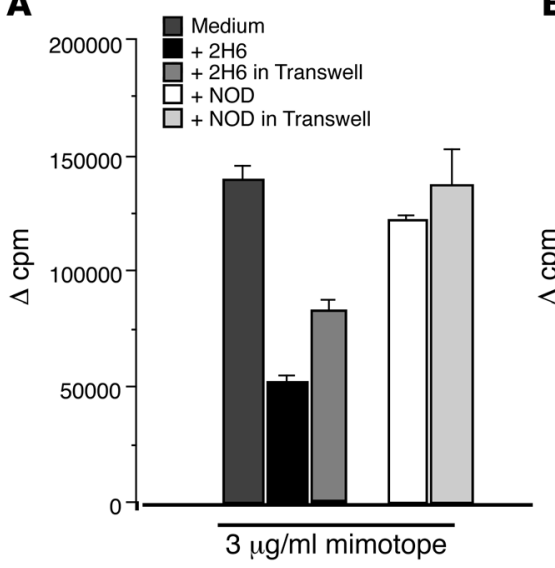

B

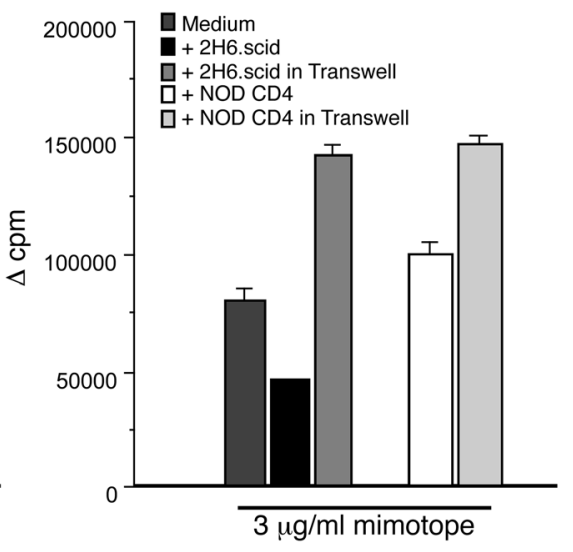

C

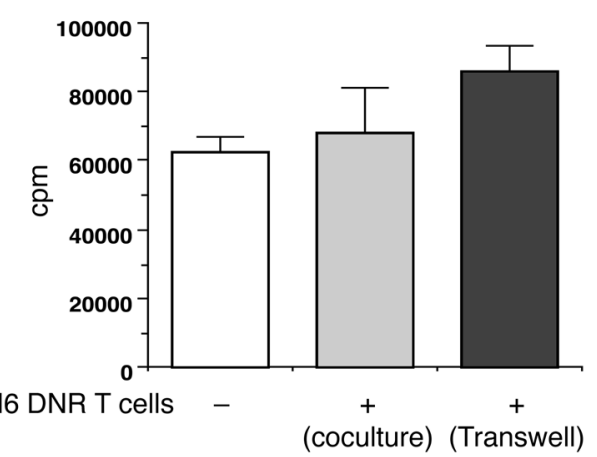

Figure 3

$2 \mathrm{H} 6$ contact-dependent and -independent suppression of BDC2.5 cells in response to the mimotope peptide. (A and B) Splenocytes from BDC2.5 transgenic NOD mice were cultured with the mimotope peptide in the presence or absence of $2 \mathrm{H} 6$ cells. The ratio of BDC2.5 cells to $2 \mathrm{H} 6$ cells was 2:1. The same culture was also performed with $2 \mathrm{H} 6$ cells in Transwells $(0.4 \mu \mathrm{m})$ to prevent the cell contact between $2 \mathrm{H} 6$ and $\mathrm{BDC} 2.5$ cells without preventing the flow of soluble factor(s). Splenocytes from $2 \mathrm{H} 6$ transgene-negative NOD mice were used as controls in the coculture system at the same ratio. A represents 1 of 3 experiments. To confirm that suppression was indeed mediated by $2 \mathrm{H} 6$ cells, the experiments were also repeated using $2 \mathrm{H} 6$ cells from $2 \mathrm{H} 6$.scid mice and purified $\mathrm{CD} 44^{+} \mathrm{T}$ cells from NOD mice as controls at the same ratio as in $\mathbf{A}$. $\mathbf{B}$ shows 1 of the 2 such experiments. Results are illustrated as $\Delta \mathrm{cpm}=$ proliferation with mimotope peptide - proliferation with medium for each of the conditions. (C) The suppression by $2 \mathrm{H} 6$ cells is completely abolished if $2 \mathrm{H} 6$ cells express a dominant-negative TGF- $\beta$ receptor (TGF- $\beta$ DNRII) (designated 2H6 DNR T cells). The abolition was seen in both coculture and Transwell culture conditions. C represents 1 of 2 experiments, and the ratio of $\mathrm{BDC} 2.5 \mathrm{~T}$ cells to $2 \mathrm{H} 6$ DNR cells was also 2:1 as for the experiment shown in $\mathbf{A}$ and $\mathbf{B}$.

unlike the parental $2 \mathrm{H} 6$ clone cells (data not shown). However, when $2 \mathrm{H} 6$ transgenic $\mathrm{T}$ cells were stimulated in vitro with anti$\mathrm{CD} 3$, they all became $\mathrm{CD} 25^{+}$(Figure 1C). This suggests that the expression of CD25 on the parental $2 \mathrm{H} 6 \mathrm{~T}$ cell clone was the result of long-term in vitro culture in the presence of IL-2.

To investigate whether transgenic $2 \mathrm{H} 6 \mathrm{~T}$ cells were functional and retained the antigen specificity of their parental clone cells, we performed in vitro proliferation assays. As shown in Figure 2A, splenocytes from randomly selected transgenic mice (5-7 weeks, 1 from line 22 and 2 from line 50) exhibited insulin reactivity in a dosedependent manner. Like the parental cloned cells, $2 \mathrm{H} 6$ transgenic $\mathrm{T}$ cells also responded to insulin B chain peptides $12-25$ and 9-23 (Figure 2B). Many mice also expressed noticeable self-reactivity, i.e., producing a high background in proliferation assays. This was not abolished even when the cells were cultured in serum-free media, AIM V (Invitrogen Corp.) and X-Vivo (Cambrex; data not shown). To investigate whether this high background was due to the low insulin content in the media, in particular in the FCS, we performed an ultrasensitive immunoassay for insulin (Linco Research Inc.). No insulin could be detected in the Click's medium without FCS, and the commonly used Click's medium with $5 \%$ FCS contains $3 \mu \mathrm{U} / \mathrm{ml}$ of insulin (which was equivalent to $1 \mu \mathrm{g} / \mathrm{ml}$ insulin protein). However, insulin could not be detected in the serum-free media, whereas 2H6 cells expressed a similar high background when cultured in these media (data not shown). The autoreactivity was also evident when splenocytes from 2H6 NOD.scid mice were tested (data not shown). These splenocytes contain $2 \mathrm{H} 6 \mathrm{~T}$ cells, splenic dendritic cells, and macrophages but are devoid of $\mathrm{B}$ cells. To prove that the autoreactivity of $2 \mathrm{H} 6$ cells is related to responses to a self-antigen other than insulin, we performed blocking experiments in which $2 \mathrm{H} 6$ cells (from both $2 \mathrm{H} 6 \mathrm{NOD}$ and 2H6 NOD.scid mice) were cul- tured in the serum-free medium X-Vivo, which had undetectable insulin in the presence or absence of $\mathrm{mAbs}$ against $\mathrm{I}^{\mathrm{Ag}} \mathrm{A}^{\mathrm{7}}$ (10.2.16), I-A ${ }^{\mathrm{b}}$ (25-9-17), CD4 (GK1.5), and control IgG (Pierce Biotechnology). The blocking results indicate that CD4 plays a critical role in the autoreactivity, as anti-CD4 completely blocked the autoreactivity and partial inhibition was also seen with anti-I-Ag7 (Supplemental Figure 2). However, anti-I-A $\mathrm{b} A b$ or control IgG did not show any inhibitory effect on the autoreactivity. These data strongly suggest that, in addition to insulin specificity, $2 \mathrm{H} 6$ cells are also reactive to an unidentified self-antigen expressed on NOD APCs.

In response to insulin or anti-CD3 stimulation, transgenic $2 \mathrm{H} 6$ $T$ cells produced a considerable amount of IL-2 (data not shown), TGF- $\beta$, and IFN- $\gamma$ (Figure $2, \mathrm{C}$ and D), a cytokine profile similar to that of their parental clone (24). It is noteworthy that $2 \mathrm{H} 6$ transgenic T cells secrete a large amount of TGF- $\beta$ and IFN- $\gamma$ even without stimulation. The fact that $2 \mathrm{H} 6$ cells are not genuinely naive and are also autoreactive could contribute to this.

CTLA-4, a negative regulator of T cell response, has been reported to be associated with TGF- $\beta$-producing Tregs (25). However, the expression of CTLA-4 on $2 \mathrm{H} 6 \mathrm{~T}$ cells did not differ from that found on $\mathrm{CD}^{+} \mathrm{T}$ cells from transgene-negative littermates (Figure $2 \mathrm{E}$ ). We also analyzed intracellular FoxP3 expression in $2 \mathrm{H} 6$ cells and in $\mathrm{CD}^{+} \mathrm{T}$ cells of transgene-negative NOD mice. It has recently been reported that expression of FoxP3 is also associated with TGF- $\beta$-producing Tregs (26). The numbers of FoxP $3^{+} 2 \mathrm{H} 6$ cells were the same as those of FoxP3 ${ }^{+} \mathrm{CD}^{+} \mathrm{T}$ cells of nontransgenic NOD mice, a similarity that resembles that found in the expression of CTLA-4 (Figure 2E).

$2 \mathrm{H} 6$ cells inhibit BDC2.5 cells in response to a mimotope through a mainly contact-dependent mechanism. BDC2.5 T cells recognize an asyet unidentified granule antigen (27). However, recently a peptide 
A

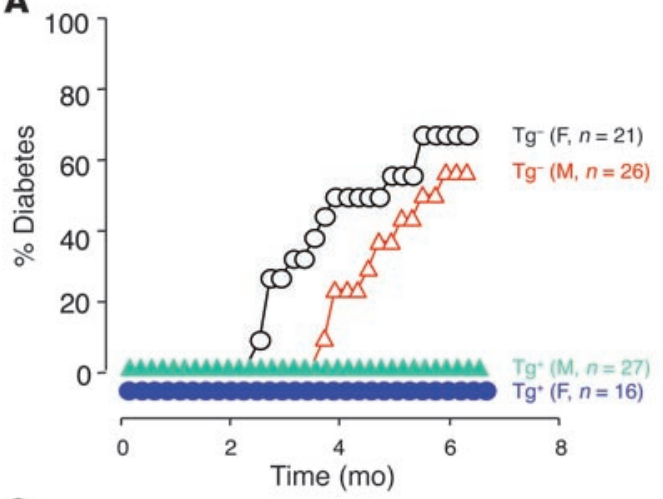

C

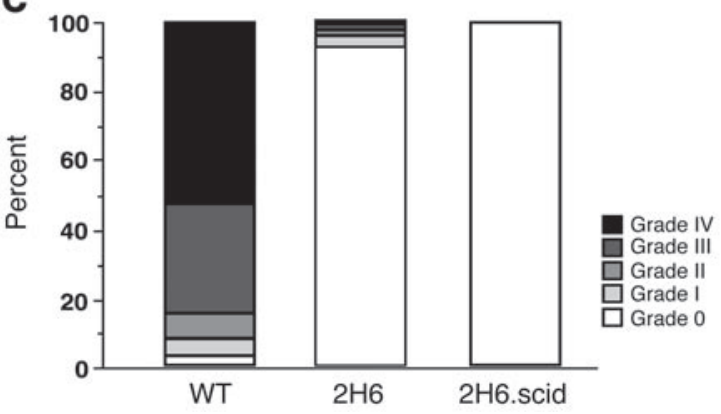

B

$\mathrm{Tg}^{-}$
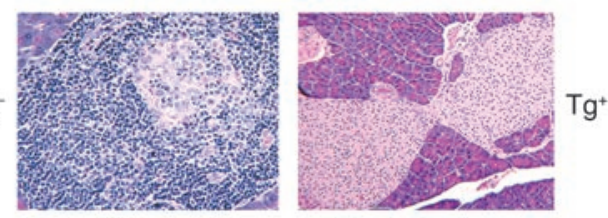

$\mathrm{Tg}^{+}$

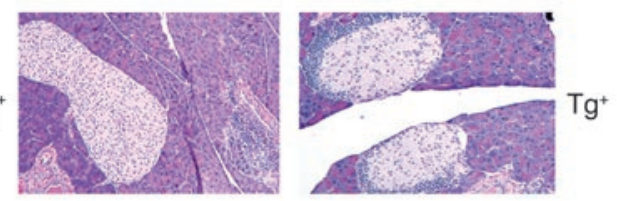

D

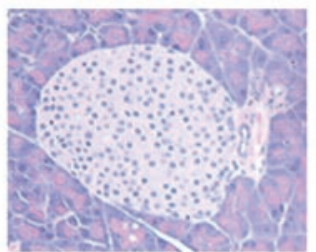

NOD.scid

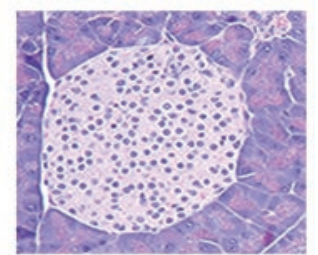

2H6 NOD.scid

Figure 4

Natural history of diabetes development and islet histology. (A) Incidence of diabetes. 2H6 TCR transgene-positive and -negative NOD mice (both sexes) were observed for diabetes development over 7 months. All the mice were monitored for glycosuria weekly, and diabetes was confirmed by blood glucose measurement (>13.9 mmol//). (B) Histology. Paraffin sections of pancreas were made, stained with H\&E, and examined for insulitis and/or islet destruction. The magnification for the transgene-negative section is $\times 100$. The magnification for the transgene-positive sections is $\times 40$. (C) Insulitis score. One hundred to 240 islets were analyzed microscopically for insulitis and scored as grade 0 (clean islets, no infiltration), grade I (peri-insulitis), grade II (mild insulitis), grade III (severe insulitis), and grade IV (complete destruction by infiltrating cells). (D) Histology. Paraffin sections of pancreas from $2 \mathrm{H} 6$.scid mice were prepared and stained with H\&E. The sections were compared with nontransgenic NOD.scid islets. The magnification is $\times 100$.

mimotope has been used to stimulate BDC2.5 T cells in vitro (28). To investigate whether $2 \mathrm{H} 6$ cells also suppress a non-insulin-specific diabetogenic $\mathrm{T}$ cell response, we stimulated BDC2.5 T cells with the mimotope peptide in the presence or absence of the $2 \mathrm{H} 6$ cells. To dissect whether the $2 \mathrm{H} 6$ effect was mediated by direct cell-cell contact or through soluble factors, such as TGF- $\beta$, we also performed coculture experiments in which $2 \mathrm{H} 6$ cells were cultured either together or in a Transwell with BDC2.5 cells in the presence or absence of mimotope. Figure $3 \mathrm{~A}$ shows that $2 \mathrm{H} 6$ cells markedly suppressed BDC2.5 cells in response to the mimotope when the cells were cultured together (64\%). However, cells from $2 \mathrm{H} 6$ mice also suppressed the proliferation of BDC2.5 cells when they were not in direct cell contact (38\%). In contrast, cells from $2 \mathrm{H} 6$ transgene-negative NOD mice did not obviously inhibit the proliferation of BDC2.5 T cells in response to the mimotope (Figure 3A). Similar contact inhibition results were obtained when $2 \mathrm{H} 6$ cells from transgenic NOD.scid mice were used (Figure 3B). It is interesting that, when tested in Transwells, 2H6 NOD.scid cells lost the inhibitory effect, suggesting that the mild inhibition seen in Transwells (Figure 3A) when cells from non-scid 2H6 NOD mice were used might be mediated by either non-T cells, such as APCs, or non-2H6 transgenic T cells. Regardless, cell-cell contact appears to play a major role in the inhibition mediated by $2 \mathrm{H} 6$ cells. To further confirm this contact-dependent suppression, we performed 2 additional sets of experiments. In the first set, we cultured BDC2.5
T cells with the mimotope peptide in the presence or absence of the $2 \mathrm{H} 6$ cells with or without mAbs against TGF- $\beta$ (R\&D Systems) or control IgG (Pierce Biotechnology). Anti-TGF- $\beta$ partially reversed the suppression, and control IgG had little effect (Supplemental Figure 3). This suggests that although the mechanism of the suppression is not totally dependent on soluble cytokines, TGF- $\beta$ may be important for the suppression. In the second set of experiments, we cultured BDC2.5 T cells with the mimotope peptide in the presence or absence of the $2 \mathrm{H} 6$ cells expressing a dominant-negative form of TGF- $\beta$ receptor type II (TGF- $\beta$ DNRII). Therefore, these $2 \mathrm{H} 6 \mathrm{~T}$ cells were not able to bind TGF- $\beta$ and trigger the signaling transduction in the cells. In this culture system, $2 \mathrm{H} 6 \mathrm{TGF}-\beta \mathrm{DNRII}$ T cells were either in direct cell contact with BDC2.5 T cells (coculture) or separated from BDC2.5 T cells (Transwell). As shown in Figure 3C, the lack of TGF- $\beta$ receptor on $2 \mathrm{H} 6$ cells resulted in loss of their ability to suppress BDC2.5 T cells in coculture. However, the lack of TGF- $\beta$ receptor did not cause $2 \mathrm{H} 6$ cells to lose the ability to produce TGF- $\beta$ (data not shown). These data indicate that the signaling induced by TGF- $\beta$ upon binding the TGF- $\beta$ receptor is important for the suppression mediated by $2 \mathrm{H} 6 \mathrm{~T}$ cells.

Inhibition of diabetes development in $2 \mathrm{H} 6$ TCR transgenic NOD mice. The natural history of spontaneous diabetes was studied in $2 \mathrm{H} 6$ transgene-positive and -negative littermates. By 30 weeks of age, the majority of transgene-negative mice (both males and females) had developed autoimmune diabetes, whereas none of the $2 \mathrm{H} 6$ 

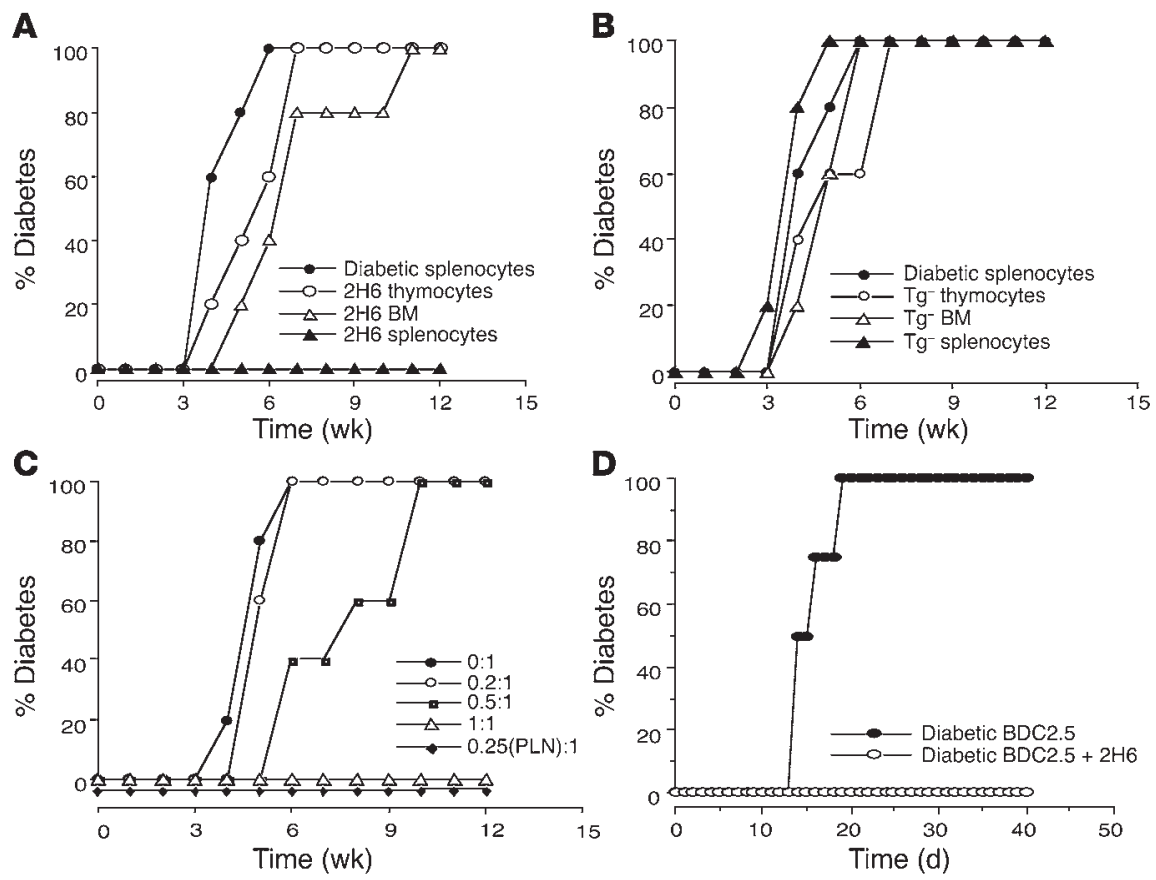

Figure 5

Adoptive transfer of diabetes. (A) Diabetic splenocytes (107 per recipient) from transgene-negative NOD mice were transferred alone (filled circles, $n=5$ ) or together with an equal number of $2 \mathrm{H} 6$ transgene-positive thymocytes (open circles, $n=5$ ), BM cells (open triangles, $n=5$ ), or splenocytes (filled triangles, $n=5$ ). (B) This graph shows the control groups of the experiment in A. Diabetic splenocytes ( $10^{7}$ per recipient) from transgene-negative NOD mice were transferred alone (filled circles, $n=5$ ) or together with an equal number of $2 \mathrm{H} 6$ transgene-negative thymocytes (open circles, $n=5$ ), BM cells (open triangles, $n=5$ ), or splenocytes (filled triangles, $n=5$ ). (C) Titration of the protective effect of $2 \mathrm{H} 6$ transgene-positive splenocytes and cells from PLNs. Diabetic splenocytes ( $10^{7}$ per recipient) from transgene-negative NOD mice were transferred alone (filled circles, $n=5$ ) or together with $2 \mathrm{H} 6$ transgene-positive splenocytes or PLN cells at different ratios: $2 \mathrm{H} 6$ cells/diabetic cells: 0.2:1 (open circles, $n=5$ ), 0.5:1 (filled squares, $n=5$ ), 1:1 (open triangles, $n=6$ ); PLN cells/diabetic cells: 0.25:1 (filled diamonds, $n=4$ ). (D) Diabetic splenocytes ( $10^{7}$ per recipient) from BDC2.5 NOD mice were transferred alone (filled circles, $n=4$ ) or together with an equal number of $2 \mathrm{H} 6$ transgene-positive splenocytes (open circles, $n=5$ ). All the mice (A-D) were monitored for glycosuria weekly, and the experiments were terminated as indicated unless the mice developed diabetes, which was confirmed by blood glucose measurement $(>13.9 \mathrm{mmol} / \mathrm{l})$.

mice (of both sexes) became diabetic by 7 months (Figure 4A) or even 10 months of age (data not shown). Since there was no difference in any of the phenotypic parameters studied between the transgenic lines, Figure 4A represents the pooled data from lines 22 and 50 and their transgene-negative littermates. In accord with the lack of diabetes development, islet pathology of 2H6 transgenic mice also showed either no islet infiltration or mild periinsulitis (Figure 4B). In sharp contrast, heavy lymphocytic infiltration could be seen in transgene-negative mice (before and after diabetes onset) as predicted (Figure 4B). We also analyzed the insulitis score, and the results correlated with the disease expression clinically (Figure 4C).

Elimination of endogenous Tregs does not affect the tolerance established by $2 \mathrm{H} 6 \mathrm{~T}$ cells. The diabetes-protective phenotype described above was derived from the studies using the $2 \mathrm{H} 6$ transgenic NOD mice. It is possible that endogenous Tregs that were not of the $2 \mathrm{H} 6$ specificity may have contributed to protection from diabetes in 2H6 TCR transgenic mice as seen in the case of diabetogenic
BDC2.5 TCR transgenic mice (29) or pathogenic myelin basic protein-specific TCR transgenic mice (30). To elucidate whether this was also true for $2 \mathrm{H} 6$ mice, we bred $2 \mathrm{H} 6$ transgenic mice to NOD.scid mice to eliminate the other endogenous potentially regulatory $T$ cells. The development and phenotype of $2 \mathrm{H} 6$ transgenic $\mathrm{T}$ cells from $2 \mathrm{H} 6$.scid mice were very similar to those seen in the $2 \mathrm{H} 6$ cells on the non-scid background (Supplemental Figure 4A), although the cellularity in the peripheral lymphoid organs of 2H6 NOD. scid mice was markedly lower than that in 2H6 NOD mice because of B cell deficiency (Supplemental Figure 4B). Diabetes development was studied in long-term (30 weeks) natural history experiments. Unlike the results obtained using pathogenic TCR transgenic mouse models, the elimination of other potential endogenous Tregs in 2H6 transgenic mice did not alter the disease-protected phenotype, as $2 \mathrm{H} 6$. scid mice were also diabetes free $(n=20$, 11 females and 9 males). In addition, islet $\beta$ cell destruction was not found in any of the mice studied (Figure 4, C and D). It is noteworthy that some $2 \mathrm{H} 6$ transgenic NOD mice expressed various degrees of insulitis whereas 2H6.scid mice were completely free of insulitis. This result also indicates that diabetes protection seen in transgenic NOD mice is due to the nature of $2 \mathrm{H} 6 \mathrm{~T}$ cells and not to the presence of endogenous potentially regulatory $\mathrm{T}$ cells expressing a nontransgenic TCR.

$2 \mathrm{H} 6$ transgenic mice are resistant to cyclophosphamide-induced diabetes. Cyclophosphamide (CY), an immunosuppressive drug, is thought to specifically eradicate immunoregulatory cells and accelerate the development of autoimmune diabetes (31). To test whether CY treatment could promote diabetes in $2 \mathrm{H} 6$ mice, we injected CY $(200 \mathrm{mg} / \mathrm{kg})$ into $2 \mathrm{H} 6$ mice and their transgene-negative littermates (6-8 weeks of age). All the mice treated with CY had transient mild weight loss, approximately 2 weeks after the injection, possibly due to side effects of the drug, such as anorexia. Six of 8 transgene-negative control littermates developed accelerated diabetes within 4 weeks after CY treatment, whereas none of the six $2 \mathrm{H} 6$ mice had developed the disease (Supplemental Figure 5) when the experiment was terminated (24 weeks after the treatment).

Inbibition of diabetes development in adoptive transfer by $2 \mathrm{H} 6$ transgenic cells. To study whether the inhibition of diabetes development in $2 \mathrm{H} 6$ mice was mediated by immune regulation or was simply due to the limited $\mathrm{T}$ cell repertoire of these mice, we performed a series of adoptive transfer experiments. Diabetic NOD splenocytes were adoptively transferred i.v. into NOD.scid mice, alone or together with lymphocytes from spleen, PLNs, thymus, and $\mathrm{BM}$ of $2 \mathrm{H} 6$ mice. Diabetes development was monitored for 

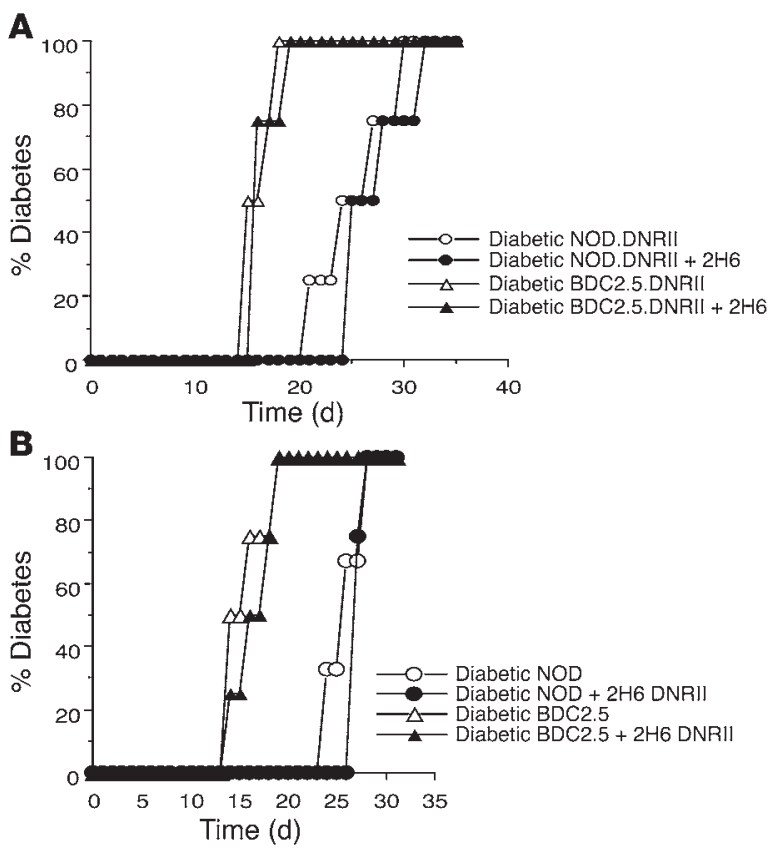

15 weeks after adoptive transfer. It is interesting that, at the indicated cell ratios, lymphocytes from spleen or PLNs of $2 \mathrm{H} 6$ mice protected the recipients from diabetes development induced by diabetogenic cells whereas $2 \mathrm{H} 6$ thymocytes or BM did not protect from disease (Figure 5, A and B). To exclude the possibility of inefficient disease protection owing to the influence of immature thymocytes, we purified CD4 single-positive thymocytes from 2H6 TCR transgenic mice and infused these cells together with diabetic splenocytes harvested from nontransgenic diabetic mice. Like total thymocyte transfer, purified CD4 single-positive 2H6 thymocytes did not protect from diabetes in co-adoptive transfer (data not shown). Our data suggest that the protective properties develop in the periphery. The PLN cells provided the strongest protection, as $100 \%$ disease inhibition could be achieved at the ratio of approximately 0.25 PLN cells to 1 diabetic spleen cell, whereas full protection could be obtained only at a 1:1 ratio when $2 \mathrm{H} 6$ splenocytes were used (Figure 5C). The number of $2 \mathrm{H} 6$ cells (double positive for TCR V $\beta 14$ and CD4) in spleen and PLNs of $2 \mathrm{H} 6$ mice was comparable $(34.86 \% \pm 8.55 \%$ and $43.82 \% \pm 14.8 \%$, respectively, $n=3$ ). The suppressive potency of PLNs was further confirmed by in vitro suppression assay using proliferation of BDC2.5 T cells as a read-out. As shown in Supplemental Figure 6, $2 \mathrm{H} 6$ cells from PLNs completely suppressed the proliferation of BDC2.5 T cells in response to mimotope, whereas PLN cells from 2H6-negative NOD mice had no inhibitory effect. In comparison with Figure 3B, where there was only $50 \%$ suppression when $2 \mathrm{H} 6$ NOD.scid spleen cells were used, $2 \mathrm{H} 6$ cells from PLNs expressed the strongest suppression (100\%). It is noteworthy that PLNs expressed the lowest number of endogenous $\mathrm{T}$ cells (Figure 1A) but showed the highest protective ability compared with splenocytes; therefore, it is unlikely that the T cells carrying endogenous TCRs contributed to disease inhibition.

$2 \mathrm{H} 6$ transgenic cells prevent diabetes development induced by BDC2.5 $T$ cells. Diabetic spleen cells contain polyclonal diabetogenic $\mathrm{T}$ cells. The disease protection by $2 \mathrm{H} 6$ cells shown above suggests that the protection is not directed solely to insulin-specific $\mathrm{T}$

\section{Figure 6}

Adoptive transfer of diabetogenic or protective cells deficient in TGF- $\beta$ receptor. (A) Splenocytes from diabetic TGF- $\beta$ DNRII NOD (open circles) or diabetic TGF- $\beta$ DNRII BDC2.5 NOD (open triangles) mice were transferred into NOD.scid recipients $\left(10^{7}\right.$ per recipient) alone ( $n=5$ for each group) or together with an equal number of $2 \mathrm{H} 6 \mathrm{NOD}$ splenocytes (filled circles and filled triangles, $n=5$ for each group). All the mice were monitored for glycosuria weekly, and the experiments were terminated when the mice developed diabetes. (B) Diabetic spleen cells from either NOD (open circles) or BDC2.5 NOD (open triangles) mice were transferred into NOD.scid recipients ( $10^{7}$ per recipient) alone ( $n=4$ for each group) or together with an equal number of TGF- $\beta$ DNRII-deficient $2 \mathrm{H} 6$ NOD cells (2H6 DNRII, filled circles and filled triangles, $n=5$ for each group). All the mice were monitored for glycosuria weekly and the experiments were terminated when the mice developed diabetes.

cells. To further test this hypothesis, we used antigen-specific (but not insulin-specific) diabetogenic T cells from the BDC2.5 transgenic mouse. Diabetic BDC2.5 TCR transgenic spleen cells were adoptively transferred into NOD.scid recipients either alone or together with $2 \mathrm{H} 6$ TCR transgenic spleen cells at a 1:1 ratio. Like the NOD.scid mice that received adoptively transferred diabetic NOD spleen cells and $2 \mathrm{H} 6$ cells, NOD.scid mice $(n=5)$ that received coinjection of $2 \mathrm{H} 6$ and $\mathrm{BDC} 2.5$ cells were diabetes free. The mice that were injected with diabetic BDC2.5 TCR transgenic spleen cells alone developed the disease within 2 weeks after transfer $(n=4$; Figure 5D).

$2 \mathrm{H} 6$ transgenic T cells suppress diabetes development in wild-type NOD mice. NOD mice expressing $2 \mathrm{H} 6$ transgene were completely protected from diabetes development (Figure 4), and 2H6 transgenic $\mathrm{T}$ cells were also able to suppress diabetes induced by diabetic splenocytes in NOD.scid recipients (Figure 5). We next sought to test whether $2 \mathrm{H} 6$ transgenic $\mathrm{T}$ cells could protect from diabetes in immune-competent wild-type NOD mice. Twenty 4- to 5-week-old female NOD mice were infused i.v. with either $2 \mathrm{H} 6$ transgene-positive $(n=10)$ or transgene-negative $(n=10)$ splenocytes $\left(10^{7}\right)$ weekly for 5 weeks. Diabetes development was then observed. The fresh ex vivo $2 \mathrm{H} 6 \mathrm{~T}$ cells from transgenic mice protected $50 \%$ of wild-type NOD mice from diabetes (Supplemental Figure 7).

Signaling of TGF- $\beta$ is important for the immune protection by $2 \mathrm{H} 6$ $T$ cells. T cells from the $2 \mathrm{H} 6$ TCR transgenic mice showed suppressive properties and produced more TGF- $\beta$ upon activation compared with those from the transgene-negative mice. To test whether $2 \mathrm{H} 6 \mathrm{~T}$ cells are dependent on TGF- $\beta$ signaling for their regulatory properties, we generated TGF- $\beta$ DNRII NOD mice and TGF- $\beta$ DNRII BDC2.5 NOD mice. T cells from these mice cannot respond to TGF- $\beta$ because of the defect in the receptor (32). TGF- $\beta$ DNRII NOD and TGF- $\beta$ DNRII BDC2.5 NOD mice develop somewhat accelerated diabetes compared with their wild-type counterparts, NOD and BDC2.5 NOD mice, respectively (M.O. Li and R.A. Flavell, unpublished data). We performed a series of adoptive transfer experiments in NOD. scid mice using diabetic TGF- $\beta$ DNRII NOD or diabetic TGF$\beta D N R I I$ BDC2.5 NOD spleen cells in the presence or absence of $2 \mathrm{H} 6$ cells. As shown in Figure 6A, $2 \mathrm{H} 6$ cells were unable to protect the NOD.scid recipients from diabetes development when the diabetogenic cells (from either TGF- $\beta$ DNRII NOD or TGF$\beta D N R I I$ BDC2.5 NOD donors) lost the ability to respond to TGF- $\beta$. This strongly suggests that diabetes protection by $2 \mathrm{H} 6$ $\mathrm{T}$ cells is mediated by the signaling of TGF- $\beta$. 
TGF- $\beta$ signaling on $2 \mathrm{H} 6 \mathrm{~T}$ cells is also important for the immune protection. To test whether the signaling of TGF- $\beta$ regulates the function of $2 \mathrm{H} 6 \mathrm{~T}$ cells in vivo, we then generated TGF- $\beta$ DNRII $2 \mathrm{H} 6 \mathrm{TCR}$ double-transgenic NOD mice. The loss of the TGF- $\beta$ receptor did not render $2 \mathrm{H} 6$ mice susceptible to diabetes; i.e., TGF- $\beta$ DNRII $2 \mathrm{H} 6$ mice were diabetes free (data not shown). However, it is interesting that $2 \mathrm{H} 6 \mathrm{~T}$ cells without TGF- $\beta$ receptor were no longer able to protect against diabetes development in the adoptive transfer model shown in Figure 6B. Although TGF-3DNRII 2H6 TCR cells did not become pathogenic T cells in the absence of TGF- $\beta$ action, this result indicates that TGF- $\beta$ signaling is important for the suppressive effect of $2 \mathrm{H} 6 \mathrm{~T}$ cells on other effector cells, as shown both in vitro (Figure $3 \mathrm{C}$ ) and in vivo (Figure 6B).

\section{Discussion}

In this study we report the generation and characterization of an insulin-reactive T regulatory TCR transgenic NOD mouse in which autoimmune diabetes mellitus development is completely prevented in both spontaneous and adoptive transfer model systems. The protection is mediated by the signaling of TGF- $\beta$ in both paracrine and autocrine fashion.

T1D onset is the result of ultimate failure in immune tolerance to islet autoantigens. Proinsulin/insulin, glutamic acid decarboxylase (GAD), and a tyrosine phosphatase-like protein known as IA-2 are major islet autoantigens targeted by both $\mathrm{T}$ cell- and $\mathrm{B}$ cell-mediated autoimmune responses (33). Recently, islet-specific glucose-6-phosphatase catalytic subunit-related protein (IGRP) has also been identified as a target for diabetogenic $\mathrm{CD}^{+} \mathrm{T}$ cells (34). Insulin, a key hormone for survival, is produced exclusively by pancreatic $\beta$ cells in large quantities. Insulin is a major autoantigen in the disease $(35,36)$ and not only appears, however, to promote diabetes development but also has the capacity to generate regulatory cells as well. To better understand how such regulatory cells might develop, we generated an insulin-reactive, regulatory TCR transgenic NOD mouse - the 2H6 NOD mouse. It is noteworthy that most, if not all, $\mathrm{CD} 4^{+} \mathrm{T}$ cells from TCR transgenic mouse strains have a pathogenic phenotype in autoimmune diabetes and other autoimmune disease models (30,37-39). Tarbell et al. have recently reported a TCR transgenic NOD mouse in which the T cells are specific for a GAD peptide. However, the mouse does not develop diabetes in spite of the fact that its lymphocytes proliferate and make IFN- $\gamma$, IL-2, TNF- $\alpha$, and IL-10 when stimulated in vitro with GAD65 peptide (40). Apart from the antigen specificity, the biological properties of the original $\mathrm{T}$ cell clone that was used to generate this transgenic mouse are unknown, as the TCR was cloned from a $\mathrm{T}$ cell hybridoma. Here, we describe the generation and characterization of a bona fide $\mathrm{T}$ regulatory TCR transgenic mouse derived from a known insulin-reactive $\mathrm{T}$ regulatory clone. The importance of this regulatory TCR transgenic mouse is that it is a unique tool that will permit the elucidation of the role for autoantigen-reactive and TGF- $\beta$-producing Tregs in autoimmune diabetes and for similar Tregs in other autoimmune conditions.

There are 3 isoforms of TGF- $\beta-\beta 1, \beta 2$, and $\beta 3$ - that have overlapping and distinct biological functions. TGF- $\beta 1$ is the most studied isoform in immunology and is also the isoform produced by $2 \mathrm{H} 6$ $\mathrm{T}$ cells. TGF- $\beta 1$-deficient mice express a severe inflammatory and autoimmune phenotype in multiple organs (41). TGF- $\beta$ receptor II is the high-affinity receptor for TGF- $\beta 1$, and mice deficient in TGF- $\beta$ receptor II specifically in $\mathrm{T}$ cells showed a phenotype very similar to that of systemic TGF- $\beta 1$-deficient mice (32). This suggests that
TGF- $\beta 1$ plays an important role in immune tolerance, especially mediated by T cells. Thus, TGF- $\beta 1$ is generally considered to be an immune regulatory cytokine with strong therapeutic potential for treatment of human autoimmune or chronic inflammatory diseases. In several animal models of human autoimmune disease, including T1D, administration of TGF- $\beta 1$ has demonstrated promising therapeutic applications (42-44). Furthermore, induction and/or enhancement of endogenous TGF- $\beta 1$ production, such as through oral tolerance, also produced a striking inhibitory effect on chronic inflammatory and autoimmune diseases, including T1D $(14,45$, 46). It has been reported that TGF- $\beta 1$ exerts immune regulatory function through cell contact-dependent or -independent mechanisms $(47,48)$. It is not clear which of these pathways $2 \mathrm{H} 6 \mathrm{~T}$ cells use to mediate their islet-specific immune tolerance in vivo, and our in vitro data suggest that cell contact-dependent mechanisms may play a major role. However, it is clear that regulation within the immune system is possible, and if manipulation can increase regulatory cell activity, then this has important implications for both prevention and treatment of autoimmune diseases; a recent study has provided evidence for proof of this principle (49).

Many insulin-reactive $\mathrm{CD} 4^{+} \mathrm{T}$ cells in the NOD mouse recognize the insulin B chain peptide 9-23 and are diabetogenic, i.e., capable of adoptively transferring diabetes $(9,10)$. It is interesting that a very potent diabetogenic $\mathrm{CD}^{+} \mathrm{T}$ cell clone, derived from a young NOD mouse, also recognizes insulin B chain 15-23 (7). Those studies suggested that $\mathrm{T}$ cells reactive to this region of the insulin $\mathrm{B}$ chain are mostly pathogenic. It is intriguing, therefore, that $2 \mathrm{H} 6$ $\mathrm{T}$ cells recognize insulin B chain peptides 12-25 and 9-23 (24), a region similar to that recognized by the insulin-reactive pathogenic T cells. In addition, $2 \mathrm{H} 6 \mathrm{~T}$ cells share the same J $\alpha$ sequence, KLTFGKGT, with diabetogenic $\mathrm{CD}^{+} \mathrm{T}$ cell clones $(9,10)$, and the same $J \beta$ sequence, YFGSGTRLTVL, with a diabetogenic $C D 8^{+} \mathrm{T}$ cell clone (7). However, unlike those pathogenic insulin-reactive $\mathrm{T}$ cells, $2 \mathrm{H} 6 \mathrm{~T}$ cells are diabetes protective and express a Treg phenotype, and the phenotype of 2H6 TCR transgenic T cells mirrors the parental cloned $2 \mathrm{H} 6$ cells. Our data provide evidence that, firstly, Tregs can be antigen specific; and secondly, both pathogenic and regulatory $\mathrm{T}$ cells can recognize a similar, if not identical, antigenic region. This is important as the information may have an impact on the design of antigen-based immunotherapy for the disease.

Insulin- or proinsulin-reactive $\mathrm{T}$ cells have also been found in patients with T1D (11). However, the in vivo biological function of those T cells is not known. Interestingly, some of the insulin- or proinsulin-reactive $\mathrm{T}$ cells found in patients with T1D showed an IL-4- and/or IL-10-producing profile (50, 51), implying protective or regulatory properties. This suggests that the autoimmune response may be downregulated. The PLN origin of $2 \mathrm{H} 6$ cells and their isolation from a diabetic mouse indicate that Tregs are present even when pathogenic T cells have destroyed most of the $\beta$ cells (24). 2 H6 TCR transgenic NOD mice are completely protected from development of diabetes. $2 \mathrm{H} 6$ transgenic cells also blocked the disease induced by diabetic spleen cells in the adoptive transfer model. Moreover, 2H6 TCR transgenic cells were able to inhibit diabetes development in an accelerated disease model. It is interesting that the protection is more likely mediated by peripheral $2 \mathrm{H} 6$ cells, as neither $2 \mathrm{H} 6$ thymocytes nor $2 \mathrm{H} 6 \mathrm{BM}$ provided disease protection.

There is no single marker that identifies a population of Tregs. Tregs are a heterogeneous group of cells. However, naturally occurring Tregs found in both humans and mice are commonly $\mathrm{CD}^{+}{ }^{+} \mathrm{CD} 25^{+}$and express FoxP3. $2 \mathrm{H} 6$ transgenic T cells do not 
express CD25 ex vivo. However, almost all the $2 \mathrm{H} 6$ transgenic $\mathrm{T}$ cells become $\mathrm{CD} 25^{+}$after stimulation in vitro. Thus, CD25 expression on $2 \mathrm{H} 6$ cells is an activation marker, not the signature of conventional Tregs. FoxP3, highly expressed in $\mathrm{CD} 4^{+} \mathrm{CD} 25^{+}$cells, has recently been considered as a master transcription factor for Tregs $(17,52)$. FoxP3 has also been reported to be induced by TGF- $\beta(26)$. It is interesting that $2 \mathrm{H} 6$ cells express very little FoxP3 even after anti-CD3 stimulation, which induces a large amount of TGF- $\beta$ production by $2 \mathrm{H} 6$ cells. This suggests that the immune regulation, in particular diabetes protection mediated by $2 \mathrm{H} 6$ cells, is not associated with FoxP3. It is possible that the $2 \mathrm{H} 6$ cell represents a nonclassical naturally occurring Treg. It is also conceivable that $2 \mathrm{H} 6$ cells represent a novel type of Treg that might have developed in the periphery and has an important immune regulatory role at the site of the immune response, given that the $2 \mathrm{H} 6 \mathrm{~T}$ cell clone was derived from diabetic PLN cells after adoptive transfer (24).

Like the parental clone, $2 \mathrm{H} 6$ transgenic cells produce a significant amount of TGF- $\beta$ in response to TCR ligation. It is noteworthy that a high level of TGF- $\beta$ was found in $2 \mathrm{H} 6$ transgenic mice even without stimulation, likely because $2 \mathrm{H} 6$ cells are also autoreactive. Increasing evidence suggests that TGF- $\beta$ is an important mediator of $\mathrm{T}$ regulatory function; however, it is not clear how TGF- $\beta$ mediates the immune regulation, such as in the case of diabetes protection by $2 \mathrm{H} 6$ cells. Using the TGF- $\beta$ DNRII model system, we were able to determine that TGF- $\beta$ signaling in the target pathogenic cells is critical for the disease suppression. It is interesting that a similar finding was reported very recently for a colitis model (53). The authors showed that TGF- $\beta$ receptor-deficient $\mathrm{CD}^{+} \mathrm{CD} 45 \mathrm{RB}^{\text {high }} \mathrm{T}$ cells escape control by diseasesuppressive $\mathrm{CD} 4^{+} \mathrm{CD} 25^{+} \mathrm{T}$ cells in vivo. Lack of TGF- $\beta$ signaling in diabetogenic $\mathrm{T}$ cells in our system somewhat enhanced their pathogenicity in both NOD and BDC2.5 NOD mice in spontaneous diabetes development and also allowed them to escape from the immune regulation by Tregs. On the other hand, the lack of TGF- $\beta$ signaling in the $2 \mathrm{H} 6$ Tregs did not change their diabetesprotective properties during the natural history of autoimmune diabetes but disarmed their ability to protect from disease development in the adoptive transfer model system.

In conclusion, our TCR transgenic model has demonstrated the mechanisms by which insulin-specific, nonclassical Tregs inhibit both spontaneous and induced diabetes development. These PLNderived cells arise naturally and do not share the common features of classical Tregs, such as the expression of CD25 and FoxP3. Instead, they represent more a Th3 phenotype and mediate immune regulation through both the paracrine and the autocrine action of TGF- $\beta$. This model system has the potential to elucidate how insulin-specific T cells downregulate islet-specific autoimmunity.

\section{Methods}

Generation of $2 \mathrm{H} 6$ TCR transgenic NOD mice. The full-length sequence of $2 \mathrm{H} 6$ TCR V $\beta 14$ was identified as $V \beta 14 / D \beta 1.1 / J \beta 2.3 / C \beta 2$. The TCR V $\alpha$ chain gene usage was first tested with 13 pairs of $V \alpha$ primers that recognize $V \alpha 1-V \alpha 13$. Although the results indicated that more than one $V \alpha$ chain was used in the parental $2 \mathrm{H} 6$ cell line, V 66 was the most dominant detected. Using a subclone of the parental $2 \mathrm{H} 6$ cells, $V \alpha 6 \mathrm{cDNA}$ was cloned and sequenced. The full-length sequence of $2 \mathrm{H} 6 \mathrm{~V} \alpha$ is $V \alpha 6 / J \alpha 45 / C \alpha$. TCR $\alpha$ and TCR $\beta$ transgenic constructs were then generated using genomic DNA of $2 \mathrm{H} 6 \mathrm{TCR}$ and cloned into the plasmid cassette vectors (54) originally provided by $D$. Mathis (Harvard University, Cambridge, Massachusetts, USA). The biological functions of both $\alpha$ and $\beta$ constructs were tested by transfection of the 2 con- structs together with a CD4 construct into 4G4 T lymphoma cells, which are defective in TCR and CD4 expression. The experimental data from the transfectants demonstrated insulin specificity of the reconstituted 2H6 TCR. The constructs were then coinjected into fertilized NOD oocytes directly (Yale Diabetes Endocrinology Research Center Transgenic Core, New Haven, Connecticut, USA), which circumvented the need for time-consuming backcrosses to NOD mice. Offspring were screened for integration of the transgenes by PCR using $2 \mathrm{H} 6 \mathrm{~V} \beta / \mathrm{J} \beta$ - and $V \alpha / \mathrm{J} \alpha$-specific primers. Three transgenic founder mice were identified and used for breeding with NOD mice to establish the transgenic colonies. The use of the animals and the procedures applied in this study was in accordance with the current National Research Council Guide for the Care and Use of Laboratory Animals and were approved by the Institutional Animal Care and Use Committee (IACUC) of Yale University.

Generation of 2 H6 TCR transgenic NOD.scid mice. 2H6.scid mice were generated by breeding of $2 \mathrm{H} 6$ TCR NOD mice with NOD.scid mice. The scid mutation was confirmed by absence of B lymphocytes in the 2H6 TCR transgene-positive mice using flow cytometry.

Generation of TGF- $\beta D N R I I N O D$, TGF- $\beta D N R I I B D C 2.5$, and TGF- $\beta D N R I I$ $2 \mathrm{H} 6$ mice. After backcrossing of TGF- $\beta$ DNRII mice to the NOD genetic background for 7 generations, the TGF- $\beta$ DNRII NOD mice were bred with BDC2.5 NOD and 2H6 NOD mice. All the transgenes were typed by PCR using genomic DNA isolated from mouse tail biopsies.

Antibodies and reagents. All the mAbs used in this study, unless indicated, were purchased from BD Biosciences - Pharmingen. All the hybridoma supernatants containing different $\mathrm{mAbs}$, used for cell purification and blocking assays, were generously provided by the late Charlie Janeway (Yale University). Magnetic beads conjugated with goat anti-mouse IgG, goat anti-mouse IgM, or goat anti-rat IgG were purchased from QIAGEN. $\mathrm{CY}$ was purchased from Sigma-Aldrich. The insulin detection kit was purchased from Linco Research Inc.

Purification of $\mathrm{CD}^{+} \mathrm{T}$ cells. After removal of erythrocytes, total splenocytes were incubated with anti-CD8 mAb (supernatant of TIB-105, rat IgG2a) on ice for 30 minutes and washed once with cold Click's medium (Gibco). The cells were then incubated with magnetic beads conjugated with goat anti-mouse $\operatorname{IgM} / \operatorname{IgG}$ and goat anti-rat IgG (BioMag; QIAGEN) on ice with gentle agitation for 45 minutes. $\mathrm{B}$ cells and $\mathrm{CD} 8^{+}$cells were removed with a magnetic plate. The purity of the $\mathrm{CD} 4^{+}$population using this method is routinely at least $90 \%$ by FACS analysis.

Proliferation and blocking assays. Splenocyte T cells $\left(5 \times 10^{4}\right.$ or $2 \times 10^{5}$ per well) were cultured in triplicate in the presence or absence of insulin as antigen for $2 \mathrm{H} 6$ cells, mimotope peptide (28) for BDC2.5 cells, or anti-CD3 (2C11) as a pan-T cell stimulator, for 3 days in 96 -well plates at $37^{\circ} \mathrm{C}$ with $5 \% \mathrm{CO}_{2}$. Irradiated (30 Gy) splenocytes, as APCs, were also added to the culture when purified $\mathrm{CD}^{+} \mathrm{T}$ cells $\left(5 \times 10^{4}\right.$ per well $)$ were used. A portion of supernatant was collected from each well before pulsing with ${ }^{3} \mathrm{H}$-thymidine, and the cultures were pulsed with $0.5 \mu \mathrm{Ci}$ of ${ }^{3} \mathrm{H}$-thymidine during the last 16-18 hours of incubation. Proliferation was measured by ${ }^{3} \mathrm{H}$-thymidine incorporation, after harvest, in a $\beta$-plate counter. Some proliferation assays were set up in the presence of a $0.4-\mu \mathrm{m}$ membrane Transwell (BD), and other proliferation assays were set up in the presence of blocking antibodies (mAb hybridoma supernatants): anti-CD4 (GK1.5), anti-CD8 (TIB-105), anti-I-Ag7 (10.2.16), anti-I-A ${ }^{b}$ (25-9-17), anti-TGF- $\beta$ (purified; R\&D Systems), and control rat IgG (purified; Pierce Biotechnology).

Cytokine analysis. The production of IL-2, IFN- $\gamma$, IL-10, and TGF- $\beta$ was investigated in the culture supernatants obtained as described above. The IL-2 production was analyzed by cytotoxic T lymphoid line assay, and ELISA was used to measure the production of IFN- $\gamma$, IL-10, and TGF- $\beta$. Monoclonal antibody pairs (purified XMG1.2 and biotin-conjugated XMG1.2) for IFN- $\gamma$ ELISA were purchased from BD Biosciences Pharmingen. An OptEIA kit was used for IL-10 detection (BD Bioscience - 
Pharmingen), and a TGF- $\beta$ kit was used for the detection of activated TGF- $\beta$ (R\&D Systems). Recombinant cytokines (IL-2, IFN- $\gamma$, IL-10, and TGF- $\beta$ ) used to generate standard curves in the cytokine assays were either provided with the kits or purchased from Invitrogen Corp.

Natural history of diabetes development. Transgene-negative or -positive NOD mice were observed for diabetes development. The mice were screened for glycosuria weekly for up to 35-40 weeks of age. Diabetes was confirmed by blood glucose (>13.9 mmol/l).

Adoptive transfer experiments. NOD.scid mice (5-7 weeks) were used as recipients in adoptive transfer experiments. Diabetic splenocytes from various donors were injected i.v. ( $10^{7}$ per mouse) alone or together with $2 \mathrm{H} 6$ transgenic cells. The mice were monitored for glycosuria biweekly after adoptive transfer, and the experiments were terminated 15 weeks after transfer unless the mice developed diabetes, which was confirmed by blood glucose (>13.9 mmol/l); these mice were sacrificed immediately. Wild-type NOD mice (4-5 weeks) were also used as recipients in some adoptive transfer experiments, in which the mice received $2 \mathrm{H} 6$ cells i.v. at weekly intervals for 5 weeks and were then monitored for diabetes development up to 35 weeks of age.

Histopathology and insulitis score. Pancreata were fixed in buffered formalin. Paraffin-embedded tissues were sectioned and stained with H\&E. Insulitis was scored under a light microscope.

1. Julier, C., et al. 1991. Insulin-IGF2 region on chromosome $11 \mathrm{p}$ encodes a gene implicated in HLADR4-dependent diabetes susceptibility. Nature. 354:155-159.

2. Pugliese, A., et al. 1997. The insulin gene is transcribed in the human thymus and transcription levels correlated with allelic variation at the INS VNTRIDDM2 susceptibility locus for type 1 diabetes. Nat. Genet. 15:293-297.

3. Gotter, J., Brors, B., Hergenhahn, M., and Kyewski, B. 2004. Medullary epithelial cells of the human thymus express a highly diverse selection of tissuespecific genes colocalized in chromosomal clusters. J. Exp. Med. 199:155-166.

4. Williams, A.J., Bingley, P.J., Chance, R.E., and Gale, E.A. 1999. Insulin autoantibodies: more specific than proinsulin autoantibodies for prediction of type 1 diabetes. J. Autoimmun. 13:357-363.

5. Skyler, J.S., et al. 2005. Use of inhaled insulin in a basal/bolus insulin regimen in type 1 diabetic subjects: a 6-month, randomized, comparative trial. Diabetes Care. 28:1630-1635.

6. Skyler, J.S., et al. 2005. Effects of oral insulin in relatives of patients with type 1 diabetes: The Diabetes Prevention Trial-Type 1. Diabetes Care. 28:1068-1076.

7. Wong, F.S., et al. 1999. Identification of an MHC class I-restricted autoantigen in type 1 diabetes by screening an organ-specific cDNA library. Nat. Med. 5:1026-1031.

8. Lieberman, S.M., et al. 2004. Individual nonobese diabetic mice exhibit unique patterns of CD8+ T cell reactivity to three islet antigens, including the newly identified widely expressed dystrophia myotonica kinase. J. Immunol. 173:6727-6734.

9. Wegmann, D.R., Norbury-Glaser, M., and Daniel, D. 1994. Insulin-specific T cells are a predominant component of islet infiltrates in pre-diabetic NOD mice. Eur. J. Immunol. 24:1853-1857.

10. Wegmann, D.R., Gill, R.G., Norbury-Glaser, M., Schloot, N., and Daniel, D. 1994. Analysis of the spontaneous $\mathrm{T}$ cell response to insulin in NOD mice. J. Autoimmun. 7:833-843.

11. Alleva, D.G., et al. 2001. A disease-associated cellular immune response in type 1 diabetics to an immunodominant epitope of insulin. J. Clin. Invest. 107:173-180.

12. Atkinson, M.A., Maclaren, N.K., and Luchetta, R. 1990. Insulitis and diabetes in NOD mice reduced by prophylactic insulin therapy. Diabetes. 39:933-937.

\section{Acknowledgments}

This work was funded by research grants from the NIH (DK53015), the American Diabetes Association, and the Juvenile Diabetes Research Foundation International. The work was also supported by the mouse genetic core of Yale Diabetes Endocrinology Research Center. F.S. Wong is a Wellcome Trust Senior Fellow in Clinical Science. M.O. Li is an American Cancer Society Postdoctoral Fellow. R.A. Flavell is a Howard Hughes investigator. We thank Fengjuan Tang for dutifully taking care of the animals used in this study and Jie Tang for the early stage of the TCR cloning. We are grateful to Aida Grozsmann for the measurement of insulin.

Received for publication October 3, 2005, and accepted in revised form January 24, 2006.

Address correspondence to: Li Wen, Department of Internal Medicine, Section of Endocrinology, Yale University School of Medicine, Mail Box 208020, 330 Cedar Street, New Haven, Connecticut 06520, USA. Phone: (203) 785-7186; Fax: (203) 737-5558; E-mail: li.wen@yale.edu.
13. Daniel, D., and Wegmann, D.R. 1996. Protection of nonobese diabetic mice from diabetes by intranasal or subcutaneous administration of insulin peptide B-(9-23). Proc. Natl. Acad. Sci. U. S. A. 93:956-960.

14. Polanski, M., Melican, N.S., Zhang, J., and Weiner, H.L. 1997. Oral administration of the immunodominant B-chain of insulin reduces diabetes in a co-transfer model of diabetes in the NOD mouse and is associated with a switch from Th1 to Th2 cytokines. J. Autoimmun. 10:339-346.

15. Maron, R., Melican, N.S., and Weiner, H.L. 1999. Regulatory Th2-type $\mathrm{T}$ cell lines against insulin and GAD peptides derived from orally-and nasallytreated NOD mice suppress diabetes. J. Autoimmun. 12:251-258.

16. Karounos, D.G., Bryson, J.S., and Cohen, D.A. 1997. Metabolically inactive insulin analog prevents type I diabetes in prediabetic NOD mice. J. Clin. Invest. 100:1344-1348.

17. Sakaguchi, S. 2005. Naturally arising Foxp3expressing $\mathrm{CD} 25+\mathrm{CD} 4+$ regulatory $\mathrm{T}$ cells in immunological tolerance to self and non-self. Nat. Immunol. 6:345-352.

18. Chen, Y., Kuchroo, V.K., Inobe, J., Hafler, D.A., and Weiner, H.L. 1994. Regulatory T cell clones induced by oral tolerance: suppression of autoimmune encephalomyelitis. Science. 265:1237-1240.

19. Burkhart, C., Liu, G.Y., Anderton, S.M., Metzler, B., and Wraith, D.C. 1999. Peptide-induced T cell regulation of experimental autoimmune encephalomyelitis: a role for IL-10. Int. Immunol. 11:1625-1634.

20. Wendling, U., et al. 2000. A conserved mycobacterial heat shock protein (hsp) 70 sequence prevents adjuvant arthritis upon nasal administration and induces IL-10-producing $\mathrm{T}$ cells that cross-react with the mammalian self-hsp70 homologue. J. Immunol. 164:2711-2717.

21. Groux, H., et al. 1997. A CD4+ T-cell subset inhibits antigen-specific T-cell responses and prevents colitis. Nature. 389:737-742.

22. Tanchot, C., Vasseur, F., Pontoux, C., Garcia, C., and Sarukhan, A. 2004. Immune regulation by self-reactive T cells is antigen specific. J. Immunol. 172:4285-4291.

23. Lepault, F., and Gagnerault, M.C. 2000. Characterization of peripheral regulatory CD4+ T cells that prevent diabetes onset in nonobese diabetic mice. J. Immunol. 164:240-247.

24. Zekzer, D., et al. 1997. Inhibition of diabetes by an insulin-reactive CD4 T-cell clone in the nonobese diabetic mouse. Diabetes. 46:1124-1132.

25. Chen, W., Jin, W., and Wahl, S.M. 1998. Engagement of cytotoxic T lymphocyte-associated antigen 4 (CTLA-4) induces transforming growth factor beta (TGF-beta) production by murine CD4(+) T cells. J. Exp. Med. 188:1849-1857.

26. Fantini, M.C., et al. 2004. Cutting edge: TGF-beta induces a regulatory phenotype in CD4+CD25- T cells through Foxp3 induction and down-regulation of Smad7. J. Immunol. 172:5149-5153.

27. Haskins, K., Portas, M., Bradley, B., Wegmann, D., and Lafferty, K. 1988. T-lymphocyte clone specific for pancreatic islet antigen. Diabetes. 37:1444-1448.

28. Judkowski, V., et al. 2001. Identification of MHC class II-restricted peptide ligands, including a glutamic acid decarboxylase 65 sequence, that stimulate diabetogenic $\mathrm{T}$ cells from transgenic BDC2.5 nonobese diabetic mice. J. Immunol. 166:908-917.

29. Kurrer, M.O., Pakala, S.V., Hanson, H.L., and Katz, J.D. 1997. Beta cell apoptosis in T cell-mediated autoimmune diabetes. Proc. Natl. Acad. Sci. U. S. A. 94:213-218.

30. Lafaille, J.J., Nagashima, K., Katsuki, M., and Tonegawa, S. 1994. High incidence of spontaneous autoimmune encephalomyelitis in immunodeficient anti-myelin basic protein $\mathrm{T}$ cell receptor transgenic mice. Cell. 78:399-408.

31. Matos, M., Park, R., Mathis, D., and Benoist, C. 2004. Progression to islet destruction in a cyclophosphamide-induced transgenic model: a microarray overview. Diabetes. 53:2310-2321.

32. Gorelik, L., and Flavell, R.A. 2000. Abrogation of TGFbeta signaling in $\mathrm{T}$ cells leads to spontaneous $\mathrm{T}$ cell differentiation and autoimmune disease. Immunity. 12:171-181.

33. Gianani, R., and Eisenbarth, G.S. 2005. The stages of type 1A diabetes: 2005. Immunol. Rev. 204:232-249.

34. Lieberman, S.M., et al. 2003. Identification of the beta cell antigen targeted by a prevalent population of pathogenic CD8+ T cells in autoimmune diabetes. Proc. Natl. Acad. Sci. U. S. A. 100:8384-8388.

35. Nakayama, M., et al. 2005. Prime role for an insulin epitope in the development of type 1 diabetes in NOD mice. Nature. 435:220-223.

36. Kent, S.C., et al. 2005. Expanded T cells from pancreatic lymph nodes of type 1 diabetic subjects recognize an insulin epitope. Nature. 435:224-228.

37. Katz, J.D., Wang, B., Haskins, K., Benoist, C., and Mathis, D. 1993. Following a diabetogenic 
$\mathrm{T}$ cell from genesis through pathogenesis. Cell. 74:1089-1100.

38. Schmidt, D., Verdaguer, J., Averill, N., and Santamaria, P. 1997. A mechanism for the major histocompatibility complex-linked resistance to autoimmunity. J. Exp. Med. 186:1059-1075.

39. Waldner, H., Whitters, M.J., Sobel, R.A., Collins, M., and Kuchroo, V.K. 2000. Fulminant spontaneous autoimmunity of the central nervous system in mice transgenic for the myelin proteolipid proteinspecific T cell receptor. Proc. Natl. Acad. Sci. U. S. A. 97:3412-3417.

40. Tarbell, K.V., et al. 2002. CD4(+) T cells from glutamic acid decarboxylase (GAD)65-specific $\mathrm{T}$ cell receptor transgenic mice are not diabetogenic and can delay diabetes transfer. J. Exp. Med. 196:481-492.

41. Shull, M.M., et al. 1992. Targeted disruption of the mouse transforming growth factor-beta 1 gene results in multifocal inflammatory disease. Nature. 359:693-699.

42. Piccirillo, C.A., Chang, Y., and Prud'homme, G.J. 1998. TGF-beta1 somatic gene therapy prevents autoimmune disease in nonobese diabetic mice. J. Immunol. 161:3950-3956.

43. Moritani, M., et al. 1998. Abrogation of autoimmune diabetes in nonobese diabetic mice and protection against effector lymphocytes by transgenic paracrine TGF- $\beta 1$. J. Clin. Invest. 102:499-506.

44. Braley-Mullen, H., Chen, K., Wei, Y., and Yu, S. 2001. Role of TGFbeta in development of spontaneous autoimmune thyroiditis in NOD.H-2h4 mice. J. Immunol. 167:7111-7118.

45. Strobel, S. 2002. Oral tolerance, systemic immunoregulation, and autoimmunity. Ann. N. Y. Acad. Sci. 958:47-58.

46. Faria, A.M., et al. 2003. Oral tolerance induced by continuous feeding: enhanced up-regulation of transforming growth factor-beta/interleukin-10 and suppression of experimental autoimmune encephalomyelitis. J. Autoimmun. 20:135-145.

47. Roncarolo, M.G., Bacchetta, R., Bordignon, C., Narula, S., and Levings, M.K. 2001. Type 1 T regulatory cells. Immunol. Rev. 182:68-79.

48. Stassen, M., Schmitt, E., and Jonuleit, H. 2004. Human $\mathrm{CD}(4+) \mathrm{CD}(25+)$ regulatory $\mathrm{T}$ cells and infectious tolerance. Transplantation. 77(Suppl. 1):S23-S25

49. Tang, Q., et al. 2004. In vitro-expanded antigenspecific regulatory $T$ cells suppress autoimmune diabetes. J. Exp. Med. 199:1455-1465.

50. Durinovic-Bello, I., et al. 2004. Pro- and anti-inflammatory cytokine production by autoimmune $\mathrm{T}$ cells against preproinsulin in HLA-DRB $1 * 04$, DQ8 Type 1 diabetes. Diabetologia. 47:439-450.

51. Arif, S., et al. 2004. Autoreactive T cell responses show proinflammatory polarization in diabetes but a regulatory phenotype in health. J. Clin. Invest. 113:451-463. doi:10.1172/JCI200419585.

52. Fontenot, J.D., Gavin, M.A., and Rudensky, A.Y. 2003. Foxp3 programs the development and function of CD4+CD25+ regulatory T cells. Nat. Immunol. 4:330-336.

53. Fahlen, L., et al. 2005. T cells that cannot respond to TGF-beta escape control by CD4(+)CD25(+) regulatory T cells. J. Exp. Med. 201:737-746.

54. Kouskoff, V., Signorelli, K., Benoist, C., and Mathis, D. 1995. Cassette vectors directing expression of $\mathrm{T}$ cell receptor genes in transgenic mice. J. Immunol. Methods. 180:273-280. 